\title{
MASTER
}

\section{LASER TWO-PHOTON EXCITED FLUOROMETRIC DETECTION FOR HIGH PRESSURE LIQUID CHROMATOGRAPHY}

\author{
Michael J. Sepaniak
}

M.S. Thesis Submitted to Iowa State University

\author{
Ames Laboratory, DOE \\ Iowa State University \\ Ames, Iowa 50011
}

Date Transmitted: December 1977

This report was preparicE

sponsored by whe prepared as an account of work United States nor the States Government. Neither the Energy, contractors, any of their employees, nor any of their any warro subcontractors, or their employees, makes liability or rexpress or implied, or assumes any lega or useful responsibility for the accuracy, completenas process diss of any information, apparatus, product intriage prively, or fepresents that its use woult infringe privately owned rights.

PREPARED FOR THE U.S. DEPARTMENT OF ENERGY UNDER CON TRACT NO. W-7405-cng-8? 


\section{DISCLAIMER}

This report was prepared as an account of work sponsored by an agency of the United States Government. Neither the United States Government nor any agency Thereof, nor any of their employees, makes any warranty, express or implied, or assumes any legal liability or responsibility for the accuracy, completeness, or usefulness of any information, apparatus, product, or process disclosed, or represents that its use would not infringe privately owned rights. Reference herein to any specific commercial product, process, or service by trade name, trademark, manufacturer, or otherwise does not necessarily constitute or imply its endorsement, recommendation, or favoring by the United States Government or any agency thereof. The views and opinions of authors expressed herein do not necessarily state or reflect those of the United States Government or any agency thereof. 


\section{DISCLAIMER}

Portions of this document may be illegible in electronic image products. Images are produced from the best available original document. 


\section{NOII CE}

This report was prepared as an account of work sponsored by the United States Government. Neither the United States nor the United States Department of Energy, nor any of their employees, nor any of their contractors, subcontractors, or their employees, makes any warranty, express or implied, or assumes any legal liability or responsibility for the accuracy, completeness, or usefulness of any information, apparatus, product or process disclosed, or represents that its use would not infringe privately owned rights.

Available from: National Technical Information Service

$U$. S. Department of Commerce

P.O. Box 1553

Springfield, VA 22161

Price: Microfiche $\$ 3.00$ 
ABSTRACT

I. INTRODUCTION

II. LITERATURE REVIEW

A. Fluorometric Liquid Chromatography Detection

B. High Pressure Liquid Chromatography on Chemically Bonded Reverse Phase Packings

C. Two-Photon Absorption

III. INSTRUMENTATION

A. Argon Ion Laser 13

B. Fluorometric Detector 17

C. Photon Counting System 19

D. Chromatographic system 21

IV. LAASER TWO-PHOTON EXCITED FLUOROMETRIC DETECTION OF'PPD, PBD, AND BBD 25

A. Experimental 25

1. Separation 25

2. Detection 27

B. Results and Discussion 31

1. Detection limits 31

2. Linearity of response 36

3. Precision 42

4. Selectivity 42 


$\begin{array}{lc} & \text { Page } \\ \text { C. COnclusions } & 43 \\ \text { V. SUGGESTIONS FOR FURTHER STUDY } & 47 \\ \text { VI. BIBLIOGRAPHY } & 50\end{array}$




\begin{abstract}
*
A filter fluorometric liquid chromatography detector is constructed using a $\mathrm{lmm}$ I.D. $\mathrm{x} 3 \mathrm{~mm}$ O.D. quartz capillary * tube as the flow cell and a laser as the excitation source. Fluorescence signals are monitored with a photomultiplier tube and photon counting system.

The detector is described and characterized for the laser two-photon excited fluorometric (LTPEF) detection of the oxadiazoles PPD, PBD, and BBD, which are separated on a reverse phase $\mathrm{C}_{18}$ column. Excitation is provided by the absorption of two photons of radiation at $5145 \%$ from an argon ion laser. The detection limits, linearity of response, precision, and selectivity are reported and are found to compare favorably with other U.V. detection methods.
\end{abstract}

*USERDA Report IS-T-774. This work was performed under Contract $w-7405-e n g-82$ with the Atomic Energy Commission 
I. INTRODUCTION

One of the reasons liquid chromatography has lagged behind gas chromatography in development has been the need for sensitive, universal detectors comparable to the kathometer, flame ionization, and electron capture detectors of gas chromatography. For this reason much of the recent work in high pressure liquid chromatography (HPLC) has centered around developing new detection systems. Discussion of various types of HPLC detectors can be found in the literature $(1-4)$.

Fluorescence detectors have been available commercially for several years but they have found only limited use, mainly because they are not as universal as certain other HPLC detectors (i.e. refractive index and U.V. absorbance detectors). However, a predictably selective detector can be useful in many analytical situations, especially when the sample matrix produres interferences with the more universal detectors.

The laser has certain attributes that make it a valuable light source in fluorometric HPLC detection. First, the spatial characteristics of the beam make it easy to concentrate almost all of the radiant output of the laser on the detector flow cell. Secondly, the large output power of the laser produces larger fluorescence signals which can 
result in lower detection limits and, as in this study, improved selectivity.

The biggest obstacle in using a laser as an excitation source for fluorometric HPLC detection is the fact that lasing action in the U.V. is fairly rare. This is a formidable problem since most compounds separated by HPLC techniques are U.V. absorbers. In the present study the proper excitation energy is attained by having the separated oxadiazole molecules absorb two photons from the $514.5 \AA$ laser line of an argon ion laser. The two-photon absorption process is rather weak and it is only the high output power of the laser that makes two-photon detection possible. The value of this detection method lies in the fact that twophoton absorption spectra differ from one-photon absorption spectra, and this produces an additional variant in the selective detection of fluorescent molecules:

The aim of thic thesis is to explore the potential of the laser in fluorometric HPLC detection. To this end research efforts which show the improved selectivity (without loss of sensitivity) of laser two-photon excited fluorometric (LTPEF) detection will be presented, followed by suggestions for further study involving additional modes of laser fluorometric detection. 


\section{IITERATURE REVIEW}

A. Fluorometric Iiquid Chromatography Detection While the U.V. absorbance detector is still the most commonly used mode of photometric $\operatorname{HPLC}$ detection $(5,6)$, the fluorometric HPLC detector has received a considerable amount of attention in recent years. The carcinogenicity of many polyaromatic hydrocarbons ( $\mathrm{PAH}$ ) is the motivation behind attempts at detecting them in the nanogram range, and the high sensitivity of fluorometric detection of compounds with appreciable fluorescence quantum efficiencies (7) makes fluorometric detection a popular method for $\mathrm{PAH}$ analysis (8-12). Fox and Staley were able to determine the concentrations of several PAH in atmospheric particulate matter in the Baltimore Harbor Tunnel using a commercial fluorometric detector (13). Their detection limit for the highly carcinogenic benzo(a) pyrene was 90pg:

There are numerous other examples of fluorometric HPLC detection. Biological samples determined by fluorometric HPLC detection include indoles in urine (14), phenols in urine (15), ergot alkaloids in blood plasma (16), and barbiturates in blood plasma (17). Many samples that are non-fluorescent can be labeled with fluorometric reagents prior to separation. Frei and Lawrence used reagents such as 4-chloro-7-nitrogenzo- 
2,1,3-oxadiazole, dansyl-chloride, and dansyl-hydrazine for the labeling, and nanogram level detection, of carbamates, ureas, organophosphorous compounds, aliphatic amines, aldehydes, ketones, and biphenyls (18). Lawrence and Frei also did further work with fluorometric pesticide detection (19).

Several commercial HPLC fluorometric detectors are reviewed in the literature $(1,20,21)$. In addition, Cassidy and Frei describe a detector consisting of a commercially available fluorimeter equipped with a small volume flow cell (22) and several other researchers have adapted spectrofluorimeters to HPLC detection $(10,16)$. Most fluorometric HPLC detectors have the same basic optical arrangement. The exciting radiation from sources such as a mercury vapor lamp, Eimac illuminator (16), or xenon arc lamp is collected then passes through either an optical bandpass filter or an excitation monochromator before being focused on a flow cell. Since long path lengths are not necessary in fluorescence measurements, flow cells are usually optical quality capillary tubes with the focused excitation beam traversing the capillary tube along its diameter. The fluorescence is collected at right angles to the exciting light beam and passed through an optical filter or an emission monochromator before being detected by 
a photomultiplier tube or other photo-sensitive device. Background signals are composed primarily of Rayleigh scattering and scattering off the highly curved flow cells. Fortunately, molecular fluorescence occurs at a lower energy than the excitation energy and it is relatively simple to discriminate between fluorescence signals and background scattering (23).

The improved sensitivity of the fluorometric detector is a result of the fact that fluorescence signals are measured over a near zero background. This is just one of the advantages of the fluorometric detector. The detector is also non-destructive, meaning small samples can be collected after separation and subjected to further analysis (13). Another advantage of the fluorometric detector is its insensitivity to flow rate and eluent composition (22), which results in the elimination of problems with pumping noise, gradient elution, and flow rate programming.

The most prominent characteristic of the fluorometric HPLC detector is its predictable selectivity (7). The detector is selective for two reasons. First, relatively few of the molecules that absorb U.V. radiation actually fluoresce, and secondly, those molecules that do fluoresce have both an excitation spectrum and an emission spectrum 
which can be used to characterize the eluted solute molecules. This advantage in detection was illustrated clearly by Vaughan, Wheals, and Whitehouse in the dedetection of PAH (10).

B. High Pressure Liquid Chromatography on Chemically Bonded Reverse Phase Packings

As a result of their low volatility or thermal instability about 80 of of the compninnds known today do not lend themselves to analysis by gas chromatography (24). This problem is not encountered when liquid chromatography is used as the separation technique. The need for the separation of non-volatile organic compounds along with advances in liquid chromatography equipment (i.e. high pressure narrow bore columns containing small uniform particle packings) has prompted extensive use of liquid chromatography in recent years $(24-26)$.

One of the must important achievements in HPLC has been the development of column packings that have organic groups chemically bonded to a silica support $(27,28)$. The silica particles are in the form of either pellicular beads or very small uniform sized particles (25). Silica is a high surface area packing composed of a tetrahedral array of $\mathrm{SiO}_{4}$ molecules. The valency requirements of the silicon atoms at the surface is partially fulfilled by 
forming silanol ( $\mathrm{Si}-\mathrm{OH})$ groups. The silanol groups are thought to be responsible for the separation properties of silica when it is used by itself as the stationary phase in liquid-solid adsorption chromatography (27). The surface of the silica can be modified by chemical reaction in several ways, one of which involves converting the silanol groups to chlorides using thionyl chloride then reacting with a suitable Grignard reagent (25).

$$
\begin{aligned}
& -\mathrm{SiOH}+\mathrm{SOCl}_{2} \rightarrow-\mathrm{SiCl} \\
& -\mathrm{SiCl}+\mathrm{RMg} \rightarrow-\mathrm{SiR}
\end{aligned}
$$

stationary phases chemically bonded to a silica support were first introduced in 1969 (29). The organic groups ( $R$ ) vary greatly depending on the desired retention characteristics. If the organic group is a $C_{1}-C_{18}$ alkyl group, then the packing will be non-polar and nonpolar solutes will be retained more strongly than polar solutes. This is referred to as a reverse phase (RP) separation and employs a polar solvent such as methanol as the mobile phase. The $\mathrm{C}_{18}$ alkyl group is the most popular RP organic group, but the shorter alkyl groups are sometimes used for separations of slightly more polar solutes or when a fast mass transfer between mobile phase and stationary phase is more important than column capacity (30). The exact mechanism of retention is not 
known for RP chemically bonded packings. One possible explanation was put forth by Karch, Sebestian, Halasz, and Engelhardt when they explained retention in terms of London dispersion forces (31).

The thermal and solvolytic stability of chemically bonded phases are among their biggest advantages (32). In liquid-liquid chromatography, a pre-column is often used to saturate the mobile phase with the stationary phase prior to its ertury into the separation column. Since bonded phases connot normally dissolve in the mobile phase, they cannot bleed away even when gradient elution is employed. This means eluents can be chosen to optimize separations without solubility considerations (33). In liquid-solid chromatography it is necessary to activate the column by heating or deactivate it by adding water so as to produce an adsorption surface with a constant activity. This is done so that separations will be reproducible and within the linear portion of the adsorption isotherm (24). With bonded phases the activity of the stationary phase remains essentially constant run aftẹ run.

Ideally a stationary phase is chosen to match as closely as possible the chemical properties of the solutes to be separated (30). Various types of RP stationary 
packings have been used in a wide variety of separations. Karch, Sebestian, Halasz, and Engelhardt describe and optimize the separation of ten mixtures important in routine work (31). Included in their work were the separations of alcohols and phenols. They separated these moderately polar compounds using a $C_{4}$ alkyl group as the chemically bonded group and a highly polar water: methanol mixture as the eluent.

Many' classes of compounds have been separated using chemically bonded octadecylsilane $\left(-\operatorname{SiC}_{18} \mathrm{H}_{37}\right)$, including herbicide residues in cotton seed oil (34), hashish extracts (35), LSD (36), quinones (37), carbamates (38), vitamins and steroids (25), and sulfa drugs (37). When separating certain aromatic compounds it is advantageous to use chemically bonded diphenyl $\left(\mathrm{si}-(\mathrm{Ph})_{2}\right)$. Actinomycins (39) and antitussives (37) have been separated with this chemically bonded RP. Rerent interest in air pollution control has prompted work in the HPLC separation and detection of $\mathrm{PA} H$. RP chemically bonded columns have been used extensively for this purpose $(9,10,13,24,35,40)$.

\section{Two-Photon Absorption}

In 1931 Maria Gopper-Mayer realized that a molecule could absorb two-photons simultaneously to achieve a 
change in its quantum level (41). The process is usually described in terms of second order perturbation theory $(42,43)$, but a simple quantum picture of the process will suffice for this treatment. If a molecule is exposed to two photons of frequencies $v_{1}$ and $v_{2}$ simultaneously, then there is probability that electrons in the molecule will oscillate at the sum of the two frequencies. If the combined frequency $\left(v_{1}+v_{2}\right)$ corresponds to a transition between quantum leveis in the molecule then the electronic oscillations in the molecule can cause absorption of the photons involved and the molecule is left in an excited state (44).

The two-photon process involves some distinctive selection rules and represents a way for spectroscopists to find and describe new molecular states. Quantum theory states that for a transition between an initial state (i) and a final state ( $f$ ) to be allowed the transition moment integral

$$
M_{i f}=\int \psi_{i}(r) \psi_{\dot{1}}^{*} d \tau
$$

must be non-zero. Consideration of the symmetries for the electric dipole moment operator $(r)$ and the states involved results in the observation that in totally symmetric molecules transitions between states of equal parity are forbidden (45). If the same treatment is made 
for the two-photon process it is found that transitions between states of equal parity are allowed, that is, in centrosymmetric molecules gerade to gerade two-photon transitions are allowed (46). The fact that two-photon absorption involves different selection rules than onephoton absorption results in different one-photon and twophoton absorption spectra.

The probability of two-photon absorption is small compared to normal absorption processes and quadratically dependent on light intensity (46). The two-photon absorption strength $(\delta)$ is defined by the relationship

$$
\Delta \mathrm{P}=\mathrm{P}_{1} \mathrm{P}_{2} \mathrm{CLA}^{-1} \delta
$$

where $\Delta \mathrm{P}$ is the absorbed optical power, $\mathrm{P}_{1}$ and $\mathrm{P}_{2}$ are the optical powers of $v_{1}$ and $v_{2}, C$ is the solute concentration, $L$ is the path length, and $A$ is the optical beam cross sectional area (44). Typical values for $\delta$ are $\leq 10^{-48} \mathrm{~cm}^{4}$ second photon ${ }^{-1}$ molecule ${ }^{-1}$.

Considering the small magnitude of two-photon absorption strengths it is not surprising that the first experimental observation of two-photon absorption did not come until 1961, shortly after the development of the laser (47). With the aid of high intensity lasers rapid progress in two-photon spectroscopy followed. Hopefield, Wariock, and Park obtained the first two-photon spectrum 
in 1963 (48). Shortly thereafter theoretical and experimental papers on the polarization properties of twophoton absorption were published $(49,50)$. Since that time much has been written on the two-photon effect including some reviews on the subject $(42,51)$ and the first experimental observation of doppler free two-photon absorption in gases (52). 
III. INSTRUMENTATION

A. Argon Ion Laser

The excitation source used in this detection scheme was a Control Laser Model 553 argon ion laser shown pictorially in Figure 1. The laser is composed of two elements; a D.C. power supply and a laser head which contains a plasma tube and optics.

The D.C. power supply serves several functions in the operation of the laser. First, it provides power to a heating filament at the plasma tube cathode. SecondIy, it provides a D.C. potential of greater than 300 volts across the anode and cathode producing a current of 25-35 amps when the plasma tube is discharging. The majority of this electrical power is dissipated as heat with a small amount converted into the radiant discharge in the tube. The power supply serves two additional functions. It supplies a several kilovolt starting pulse to initiate discharge in the tube and it also supplies power to a solenoid which helps to produce a positionally more well-defined discharge.

The laser head contains the principal component of the laser which is a tungeten bore plasma tube. The plasma tube consists of tungsten discharge constricting discs separated by quartz spacers, a quartz tube to hold 


\section{THIS PAGE}

WAS INTENTIONALLY

LEFT BLANK 
Figure 1. Schenatic diagran of laser two-photon excited fluoromatric detector. The ortec photon counting system is outlined by the dashec line. 


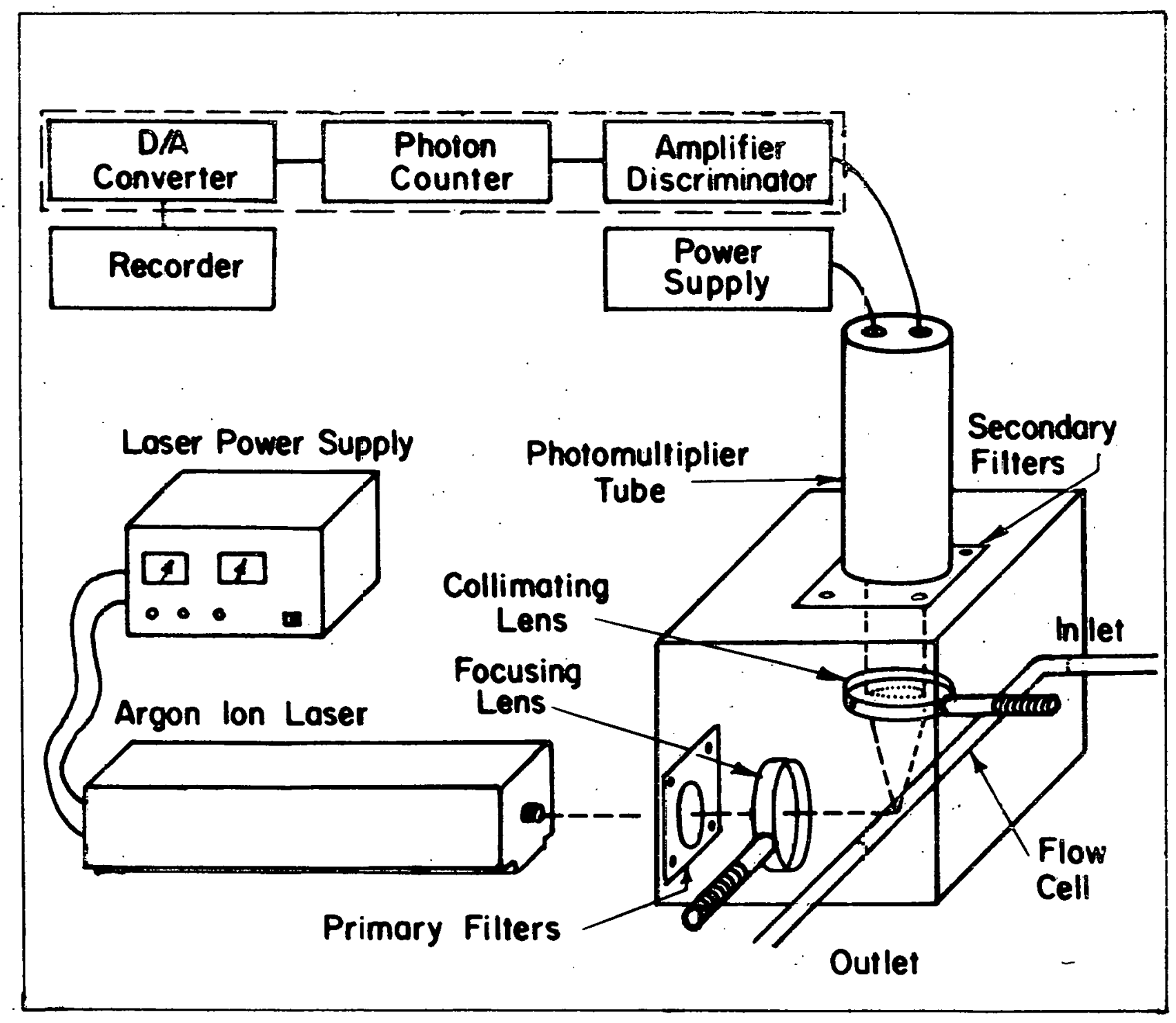

宑 
the tungsten discs and electrodes, and optically contacted quartz Brewster windows. The plasma tube is supported by a cooling line and the solenoid. The laser head also contains, at its ends, the optics which provide a regenerative path for the laser light through the plasma tube. The optics are a front mirror which is approximately $10 \%$ transmittive and a rear mounted littrow prism used to select the $5145 \AA$ laser line used in this study.

Laser action is generated by the plasma discharge which produces a population inversion in the ionized argon. Optical gain at wavelengths corresponding to certain transitions in the ionized argon is produced via stimulated emission by providing a regenerative light path through the plasma. The littrow prism in the rear of the laser head is a wavelength dispersive element which can be used to select for lasing one of the many argon ion emission lines present in the plasma.

Lasing action is initiated by the following sequence of steps. First, a cooling water flow of 2.5-3.0 gallons per minute at a pressure greater than 30 psi is maintained. Next, the laser is turned on and filament heat is supplied until the cathode has reached its proper. temperature. When the cathode has attained the proper temperature and the solenoid and electrode potentials have been applied a start button becomes illuminated. 
Depressing the start button results in a several kilovolt starting pulse which produces a discharge in the plasma tube. If the laser optics are properly aligned lasing should occur. In the event lasing does not occur, adjustment of the horizontal and vertical controls in the rear of the laser head will cause lasing in most instances. Both the discharge current and the radiant output of the laser are monitored by meters on the front panel of the power supply.

The laser can be controlled in either of two modes. In the first mode the radiant output power of the laser is adjusted by setting the discharge current with a current control knob. The laser is protected against overloading by automatically shutting down at currents greater than 35 amps. In the second mode of operation the radiant output power is controlled by a servo mechanism which keeps the radiant output at the power set by a servo control knob. The latter mode of operation permits slight optical misalignment without affecting the radiant output power.

\section{B. Fluorometric Detector}

The fluorometric detector (see Figure 1) was constructed from a light tight, 6-inch cubic metal con- 
tainer. The main component of the detector is a Imm I.D. $x 3 \mathrm{~mm}$ O.D. quartz flow cell with a total volume of $120 \mu 1$. The flow cell was flared at its ends by the Iowa state University glass shop and then fitted with glass connectors from Altex Scientific, Inc. The detector also contains two quartz lens: one a $50 \mathrm{~mm}$ focal length by $25 \mathrm{~mm}$ diameter focusing lens and the other a $38 \mathrm{~mm}$ diameter collection lens with an f-number of one. Both lenses are positioned by lens holders constructed by the Ames Laboratory metal shop.

The detector is a filter instrument with the secondary filters held between a large hollowed aluminum disc and the photomultiplier tube aperture of the detector. The primary filters were either taped over the outside of the light input aperture or positioned in a filter holder just inside the detector. Problems with light scattering arc reduced by painting the inside of the detector with ultra flat black paint and by placing light baffles (not shown in Figure 1) in the detector. As in most fluorometric detectors the scatter is also minimized by collecting fluorescence at right angles to the excitation beam. 


\section{c. Photon Counting System}

In this study, fluorescence signals were processed by a photomultiplier tube and photon counting system. The photomultiplier tube (PMT) is now used extensively in spectrophotometric work and in most instances the output of the PMT is monitored by analog techniques (53). At first glance the digital processing of fluorescence signals (photon counting) with subsequent digital to analog conversion may seem to be an indirect way of monitoring fluorescence signals. However, this is not the case since at low light levels the discrete nature of the fluorescence is evident and, in fact, photon counting possesses some distinct advantages over the more commonly used analog techniques (54). These advantages include improved signal to noise ratio, long term stability which is a result of the insensitivity of photon counting to voltage and temperature changes, and the possibility of signal integration (chromatographic resolution is the limiting factor here). These. advantages along with the availability of a photon counting system prompted its use in this study.

The photomultiplier tube used was an Amperex 56DVP which was housed in a dry-ice cooled housing from Pacific Photometric Instruments and powered by a Model 242 
regulated high voltage supply from Keithley. The 56DVP has a photosensitive response which extends in the U.V. to about $300 \mathrm{~nm}$.

The pulses from the PMT were processed by an ortec NIM photon counting system composed of a Model $402 \mathrm{M}$ power supply, Model 9302 amplifier discriminator, Model 9315 photon counter, and Model $9325 \mathrm{D}-\mathrm{A}$ converter. The components were housed, along with a latching circuit. constructed at the Ames Laboratory, in a Model $401 \mathrm{M}$ minibin. The 9302 amplifier-discriminator features a wideband 20 or 200 gain amplifier and integral discriminator. The discriminator, which can be set between 0.05 volts and 1.0 volts, can receive the amplified -pulses from the PMT at a rate up to $100 \mathrm{MHZ}$. The standard NIM negative going pulses from the discriminator are accepted and counted by the 9315 photon counter. The 9315 is a triple width NIM module that includes two counters. In normal operation the $B$ counter serves as a timer with the capability of counting in increments as small as lms. The rear panel of the 9315 has a parallei output which is connected to the Model 9325 D-A converter via an Amphenol 57-40360 connector. The 9325 generates an analog output of $0-10 \mathrm{~V}$ or $0-0.1 \mathrm{~V}$ that is proportional to any three selected decades of 
digital data in the photon counter. The 9325 also includes an adjustable (3ms-10s) time constant.

The $9325 \mathrm{D}-\mathrm{A}$ converter is not designed to hold the digital count of the photon counter while a new count is being accumulated. This shortcoming was remedied by introducing a latching circuit which retains the previous count until it is cued that a new count is ready through the parallel output connector of the photon counter. The output of the D-A converter was fed to an Ominiscribe stripchart recorder.

\section{Chromatographic System}

All separations were made on the chromatographic system shown in Figure 2. The column was a $3.9 \mathrm{~mm}$ I.D. $x$ $30 \mathrm{~cm}$ long prepacked $\mu$ bondapak $\mathrm{C}_{18}$ column from Waters Associates. The reverse phase packing used in this column is composed of highly porous $10 \mu \mathrm{m}$ diameter silica gel particles with ODS $\left(-\mathrm{C}_{18} \mathrm{H}_{37}\right)$ groups chemically bonded to its surface. The column has a reported minimum plates per column of 3000 for acenaphthene when eluted with $60: 40, \mathrm{CH}_{3} \mathrm{CN}: \mathrm{H}_{2} \mathrm{O}$ (55).

Injections were made via a Rheodyne Model 7120 syringe loading sample injector. The model 7120 injector is a 6 port rotary valve injector designed for operation 


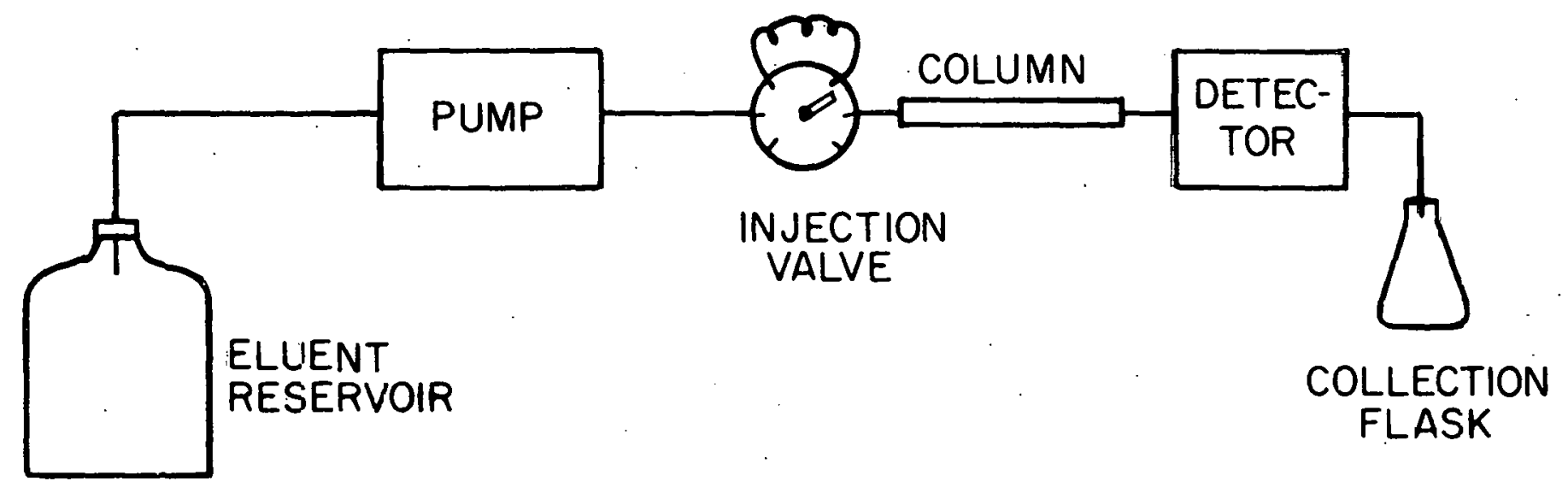

Figure 2. Chromatographic system including a LDC mini pump, Rheodyne injector, and Waters Associates $C_{18}$ HBondapak column. 
at pressures up to $7000 \mathrm{psi}$. The sample injector was fitted with a $100 \mu l$ sample loop which was loaded with a syringe through a needle port built into the valve rotor and shaft. 'This injector is versatile in that injections of less than $100 \mu 1$ can be made by either switching to a smaller injection loop or by using a microsyringe to inject a quantity of sample less than $100 \mu 1$ into the sample loop.

Eluent was pumped from an acid bottle reservoir by a LDC Model 396-2396 minipump. The mintpump is a reciprocating plunger, positive displacement pump capable of delivering $16-160 \mathrm{ml}$ per hour of eluent at pressures up to 5000 psi. Flow rate was adjusted by a micrometer dial which controls the stroke length of the pump. The dial is divided into percent units but it was found that increasing the dial beyond $75 \%$ did not result in increased flow since the pressure drop across the column at this setting was at the limit of the pump. Since pump flow rate settings were found to be non-reproducible and no flow meters were available for the chromatographic system, it was necessary to measure flow rates by collecting eluent in a graduated cylinder over a suitable period of time.

All connections were made with tubing purchased 
from Altex Scientific, Inc. Connections between the minipump, injector, and column were made with 1/16" diameter ss tubing. The eluent reservoir was connected to the minipump by $1 / 8 "$ diameter teflon tubing which was terminated at the eluent reservoir end with a porous fritted disc and the detector connections were made with $1 / 16^{\prime \prime}$ teflon tubing. 


\section{LASER TWO-PHOTON EXCITED FLUOROMETRIC DETECTION OF PPD, PBD, AND BBD}

\section{A. Experimental}

\section{Separation}

All separations were performed on the chromatographic system show in Figure 2. The oxadiazoles separated have the following general structure<smiles>[R]c1nnc([R])o1</smiles>

where $R$ and $R^{\prime}$ are either phenyl or biphenyl groups. Since the polarity of the oxadiazoles vary greatly depending on the attached groups, it was necessary to use a relatively non-polar 60:40,THF:Water eluent to successfully reversephase separate the oxadiazoles, in a reasonable length of time. The oxadiazoles were purchased from Pfaltz and Bauer, Inc., the THF was from Burdick and Jackson, and the water was distilled and deionized water from Iowa State University. The eluent was also used as the solvent for the oxadiazoles. To illustrate the selectivity of the detector several $\mathrm{PAH}$ were also dissolved in the eluent and injected along with the oxadiazoles. Because of the low solubility of the oxadiazole BBD (approximately $7 \mathrm{mg}$ per liter in 60:40, THF: water) it was necessary to use a fairly large injection volume 
of $100 \mu 1$. The large injection volume made it possible to inject an absolute quantity of $B B D$ large enough to be detected, but it also tended to produce rather broad peaks. Fortunately, Chromatographic resolution of the oxadiazoles was not a problem and complete separation could be accomplished even with the $100 \mu 1$ injection volume.

In liquid chromatography a van Deemter type plot yields an optimal HETP at a flow rate which is too slow to be practical. But the plot is sloped only slightly and, therefore, it is customary to use flow rates that produce pressures near the limits imposed by the chromatographic system components. In this study a flow rate of $2.0 \mathrm{ml}$ per minute (measured by a collection method) was used.

The chromatographic detector investigated in this study was evaluated by performing the following sequence of steps. An initial rough separation was used to improve on separation parameters and to estimate detection limits. With this information several solutions of each oxadiazole were prepared and injected in order to determine detection limits and linearity of response. Then a suitable mixture of the oxadiazoles was prepared and repeatedly separated with and without the addition of 
several PAH as interferences. This was done to evaluate the reproducibility and selectivity of the detector. Finally, the steps were repeated using a U.V. absorbance detector as a comparison. The results of these steps are presented in the Results and Discussion section.

\section{Detection}

In this study separations were monitored with either a Chromatronix mixed wavelength absorbance detector or a laser two-photon excited fluorometric (LTPEF) detector: The absorbance detector was operated at $280 \mathrm{~nm}$ where background noise was smallest and oxadiazole absorptivities greatest. The column was connected to the detectors by a 6 inch piece of 1/16" O.D. teflon tubing.

The LTPEF detector is shown in Figure 1 and described in the Instrumental section. The $5145 \%$ radiation of the argon ion laser passes through two Corning 3-71 sharp cut-off filters taped over the outside of the fluorometric detector input aperture, then through one Corning 4-96 wide bandpass filter which is held by the primary filter holder just inside the detector. The radiation is focused on the center of the flow cell by the focusing lens and the resulting fluorescence is collected and collimated by the collection lens. The collimated 
fluorescence is passed through three U.V. bandpass secondary filters (two corning 7-51 filters and one Corning 7-54 filter) then onto the photocathode of the PMT. The purpose of the corning 3-71's is to eliminate laser plasma lines present in the laser super-radiance (56) and the corning 4-96 is used to block orange fluorescence from the Corning $3-71^{\prime} \mathrm{s}$ which is passed by the secondary filters. This and other spectral considerations are illustrated in Figure 3.

Fluorescence signals were counted in $0.5 \mathrm{~s}$ intervals with the ortec photon counting system. The photon counter dwell time was turned off and the $D-A$ converter time constant was set at 0.1 , since it was found that longer time constants and dwell times decreased detector precision.

Prior to chromatographic operation the LTPEF detector optics were optimized and standardized by placing a stagnant solution of $10^{-3} \mathrm{M}$ PPD in the flow cell, then adjusting the optics (the lens holders shown in Figure 1 provide slight adjustment of the optics) to give a photon count of 20,000 counts per second at a laser power of 1 watt. The focusing lens adjustment was critical but once set, the system remained stable until other experimental operations required moving the laser. The 


\section{THIS PAGE}

\section{WAS INTENTIONALLY \\ LEFT BLANK}


Figure 3. Speztral considerations for the LTPEF detector. Upper graph: Transmission Elrves for primary filters 3-71 and 4-96 and secondary filters 7-51 and 7-54. Lower graph: Fluoreszence emission regions for PPD, PBD, and BBD. The super radiance $c \pm$ the laser contains argon ion emission in the ræagion from $3500 \AA$ to $5145 \AA$. 


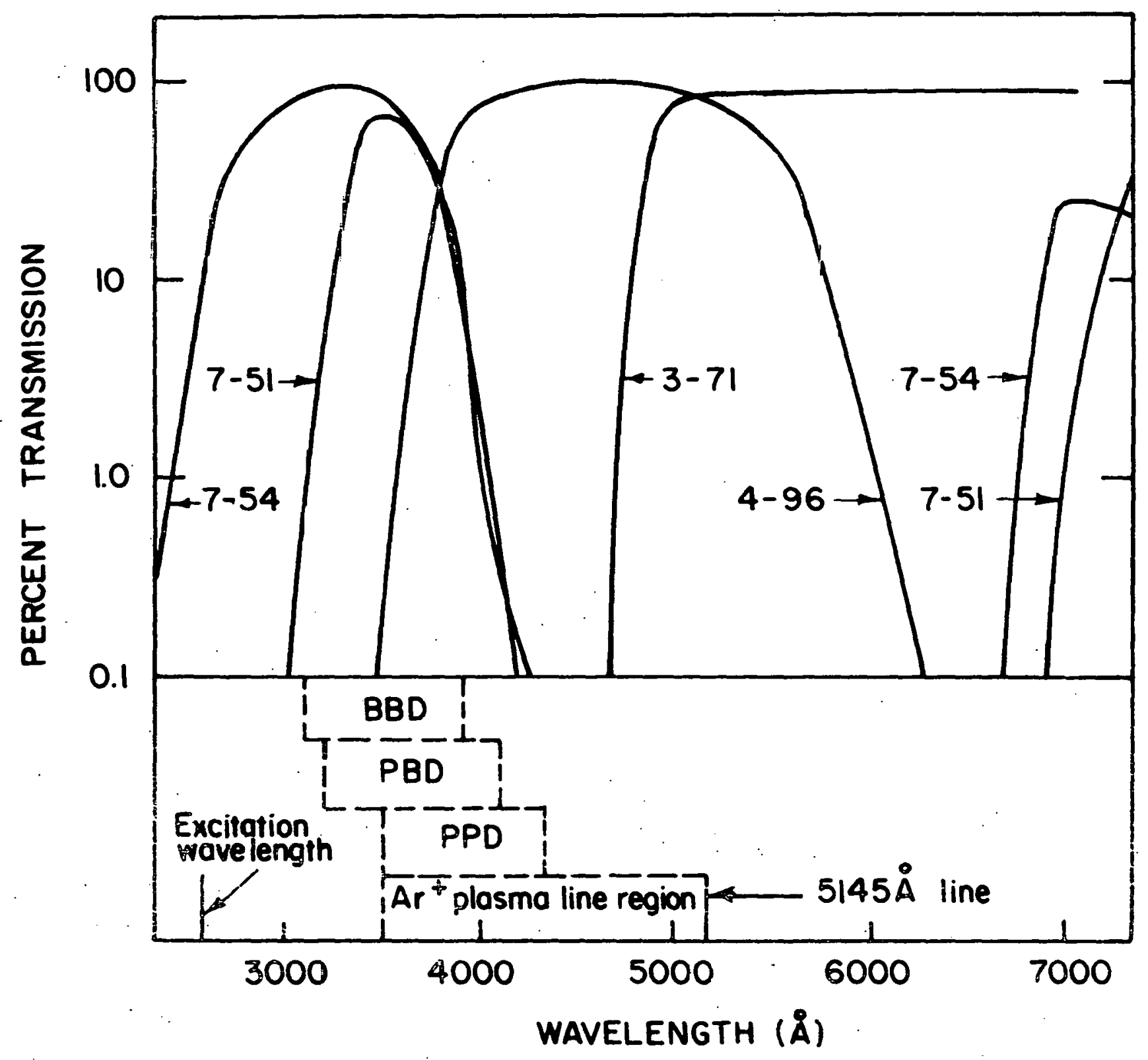

w 
laser was operated in the servo mode with all separations performed at a laser power of 4 watts.

\section{B. Results and Discussion}

1. Detection limits

The concentration necessary to detect a particular solute with a given response can be calculated using equation 2 and the following equation

$$
\mathrm{R}=\mathrm{Qkq}
$$

which relates the fraction of absorbed optical power that is registered as fluorescence $(R)$ to the solute fluorescence quantum efficiency $(Q)$, the optical collection efficiency $(k)$, and the detector quantum efficiency $(q)$. For the present detection system $R$ is approximately $10^{-3}$, L the diameter of the flow cell is $0.1 \mathrm{~cm}$, and $A$ the cross sectional area of the focused laser beam is roughly $10^{-4} \mathrm{~cm}^{2}$. Using these quantities the concentration necessary to register a photon count of 100 counts per second, at a power of 4 watts (5145\%) for a solute with an absorption strength of $10^{-48} \mathrm{~cm}^{4}$ second photon ${ }^{-1}$ molecule ${ }^{-1}$, is $1.5 \times 10^{-9} \mathrm{M}$. As seen from this calculation sub parts-per-million concentrations can, in principle, be detected even for solutes with moderate two-photon absorption strengths, providing 
high laser output power can be obtained at the proper absorbing frequency.

In the previous calculation a relatively small photon count of 100 counts per second was chosen as an easily detectable signal. This is mainly due to the ease with which optical filters can be used to reduce background signals. The laser light is better separated, spectral1y, from the fluorescence (see Figure 3) than in normal one-photon excited fluorescence.

The detection limits of the two detectors employed in this study were determined by observing where a straight line plot of signal to noise ratio vs concentration intersects a signal to noise ratio of 3 (see Figure 4). The favorable detection limits of the LTPEF detector are shown in Table I where detection limits for two of three oxadiazoles are better for the LTPET deteotor.

Table I. Detection Iimits

U.V. absorbance detector LTPEF detector

PPD

PBD

BBD
$13 \mathrm{ng}$

$10 \mathrm{ng}$

$76 \mathrm{ng}$
150 ng

9ng

3 Ing 
THIS PAGE WAS INTENTIONALLY LEFT BLANK 
Figure 4. oxadiazole detection limits for; A,a,PPD; B,b,PBD; C,C,BBD. Upper case letters LTPEF detection, lower case letters U.V. absorbance detection. 


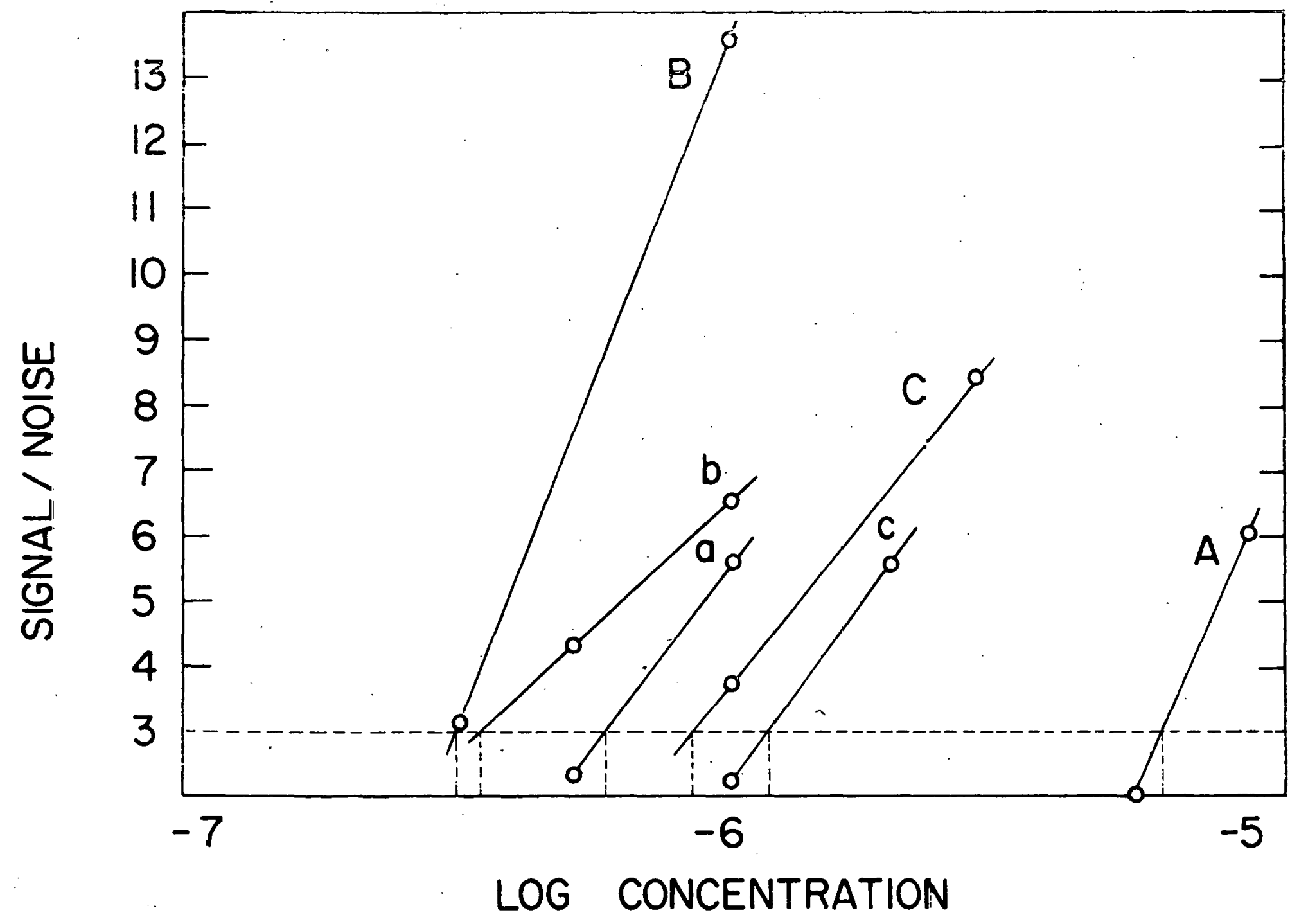


The peak to peak background noise, and therefore the detection limits, of the U.V. absorbance detector could be improved by effective eluent pulse dampening, but the improvement is limited by detector drift and fluctuations other than the regular pumping noise of the system. And, in fact, the elimination of pumping noise, solvent peaks, detector drift, and problems with gradient elution are some of the distinct advantages of the LTPEF detector.

There are a few LTPEF detector improvements that should in theory improve sensitivity. The first is to replace the primary filters by a good quality dispersive prism, which would remove plasma lines from the laser super radiance with approximately $40 \%$ less beam attenuation than with the filters. The second is to use a focusing lens with a shorter focal length. The theoretical limit of the cross sectional area of the focused laser beam ( $A$ in equation 2 ) is dependent on the focusing lens (57). With a shorter focal length lens, higher power densities, and therefore larger twophoton absorption, could be obtained. The quadratic dependerice of two-photón signals on lascr power is shown in equation 2. A third improvement would therefore be increasing the laser output power by means of a mode lookcr. The reader is referred to reference 56, p. 199 
for a good description of mode locking. When mode locked the continuous output of the argon ion laser is converted to a series of high energy pulses. Sensitivity could then be greatly enhanced by properly gating the detection system so that signals are counted only during and directly after a laser pulse. Even without gating the detector a two-fold increase in signal could result from mode locking.

\section{Linearity of response}

The linearity of response of the LTPEF detector was compared to the U.V. absorbance detector by making $100 \mathrm{pl}$ injections of $3.0 \times 10^{-7} \mathrm{M}$ to $1.0 \times 10^{-3} \mathrm{M}$ PBD. The responses of the detectors to the injections are shown for the LTPEF detector in Figure 5 and the U.V. absorbance detector in Figure 6 . In Figure 7 calibration plots are drawn for both detectors. The inner-cell effect often times causes non-linearity in fluorometric detection (1), but the small active cell length (about $1 \mathrm{~mm}$ ) and large incident radiation of the LTPEF detector results in a linear calibratiun wurve for PBD, even at solubility limited concentrations. The linear regression constants for the calibration plots were 0.984 for the U.V. absorbance detector and 0.987 for the LTPEF detector, showing equally good linearity. 
Figure 5. LTPEF detector peaks for PBD. Eluent 60:40, THF: water, flow rate $2.0 \mathrm{ml}$ per minute, laser power 4 watts at $5145 \AA$, and count time $0.5 \mathrm{~s}$.

Weight Injected

$(\mu \mathrm{g})$
A $\quad 8.94 \times 10^{-3}$
125
B $2.98 \times 10^{-2}$
125
C $2.98 \times 10^{-1}$
125
D $8.94 \times 10^{-1}$
1250
E 2.98
1250
F $\quad 8.94$
12500
G $\quad 29.8$
12500

Sensitivity

(counts/inch) 


\section{THIS PAGE}

WAS INTENTIONALLY

LEFT BLANK 


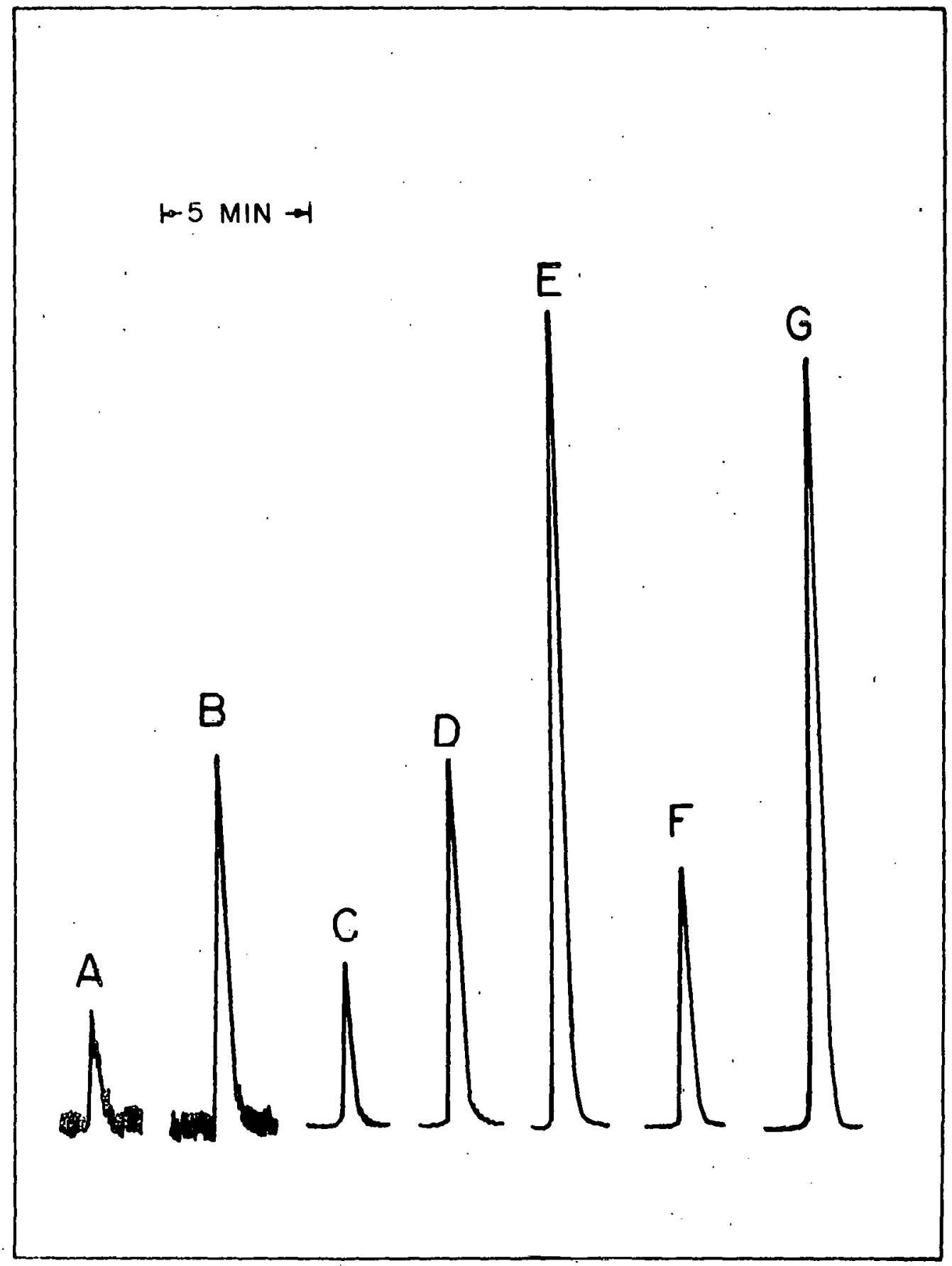


Figure 6. U.V. absorbance detector peaks for PBD. Eluent $60: 40$, THF : water, flow rate $2.0 \mathrm{ml}$ per minute, and absorbing wavelength $280 \mathrm{~nm}$.

Weight Injected $(\mu \mathrm{g})$
A $\quad 1.29 \times 10^{-2}$
B $\quad 2.98 \times 10^{-2}$
0.005
C $8.94 \times 10^{-2}$
0.005
D $2.98 \times 10^{-1}$
0.005
E $8.94 \times 10^{-1}$
F $\quad 2.98$
G $\quad 8.94$
$\mathrm{H} \quad 29.8$
0.005
0.01
0.04
0.16
0.32

Sensitivity
(absorbance units/inch) 


\section{THIS PAGE}

\section{WAS INTENTIONALLY \\ LEFT BLANK}




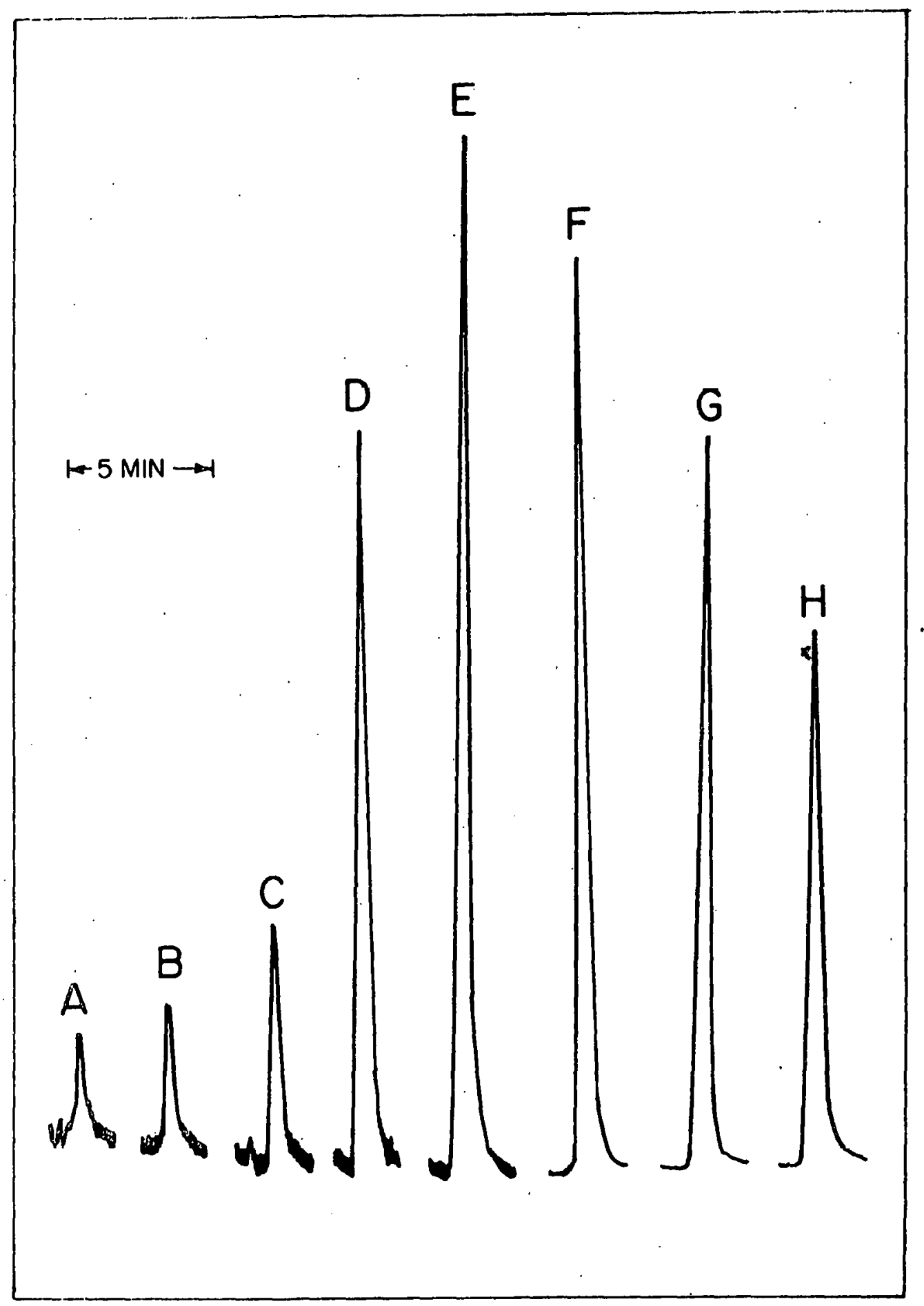




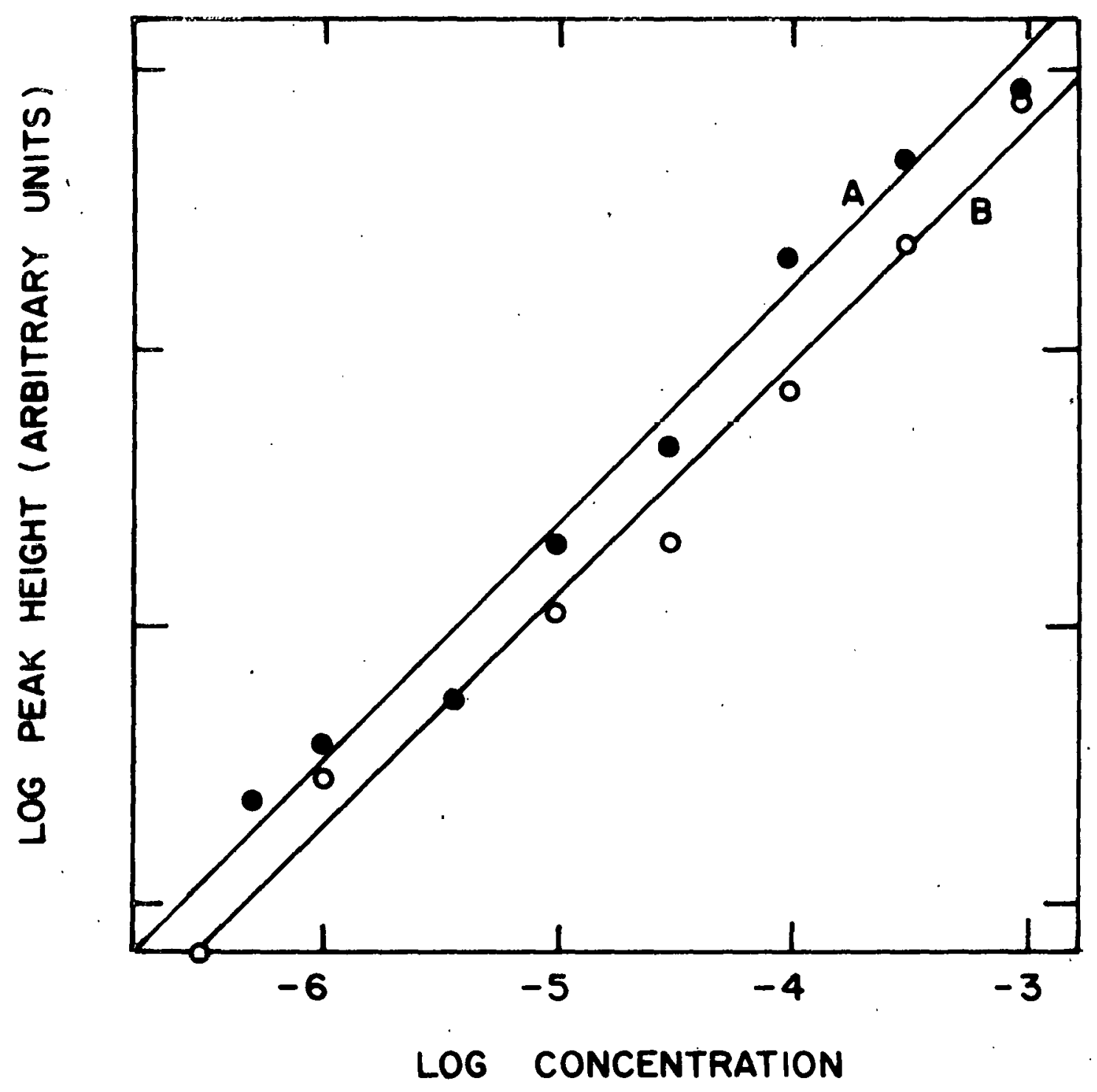

Figure 7. Calibration plots for PBD: A (solid circles) U.V. absorbance detector, B (open circles) LTPEF detector. 


\section{Precision}

The precision of the detection system was evaluated by making 5 injections of the three oxadiazoles at the concentrations listed in Fiqure 8 . The peak heights were measured and the $\mathrm{BBD}$ peaks were used as internal standards. This was done so that only inconsistencies resulting from detector response would be considered. The relative standard deviation for the five PPD and PBD peake were 6.78 and 10.18 respectively. The LTPEF detector reproducibility compares favorably with that reported by Perchalski, Winefordner, and Wilder for a fluorometric HPLC detector (16), but is not as good as the reproducibility of a fluorometric detector reported by Cassidy and Frei (22). Inconsistencies in ITPEF detector response can be attributed, in part, to the non-linear dependence of two-photon signals on laser power density, which makes beam and power stability critical to reproducibility. Better reproducibility could be attained if fluorescence signals were normalized to laser power output using equation 2 .

\section{Selectivity}

The selective detection of the oxadiazoles PPD, $\mathrm{PBD}$, and $\mathrm{BBD}$ is illustrated in Figure 8. Chromatograms 
$8 \mathrm{a}$ and $8 \mathrm{~b}$ are essentially identical despite the fact that the sample injected in $8 \mathrm{~b}$ contains several $\mathrm{PAH}$ at concentrations of approximately $10^{-5} \mathrm{M}$. The same separations in Figure 9 show appreciable interference effects for the U.V. absorbance detector. In Figure $9 \mathrm{~b}$ the PBD peak is almost totally obscured by the PAH and the PPD peak is unresolved as well. The PAH were chosen so that the BBD peak was not interfered and could be used as an internal standard.

At this point the selectivity of the LTPEF detector is limited by the availability of laser output frequencies. The present detector employs an argon ion laser which has several visible plasma lines between $4579 \AA$ and $5145 \%$. To take full advantage of the uniqueness of two-photon spectra, lasing action must be attained at two-photon frequencies covering most of the near U.V. region of the spectrum. This sould possibly be done with high output power tunable dye lasers.

\section{Conclusions}

While two-photon absorption strengths are very small, molecular two-photon states are as common as one-photon states. This means that LTPEF detection can be applied to most fluorescent compounds provided a laser can be 


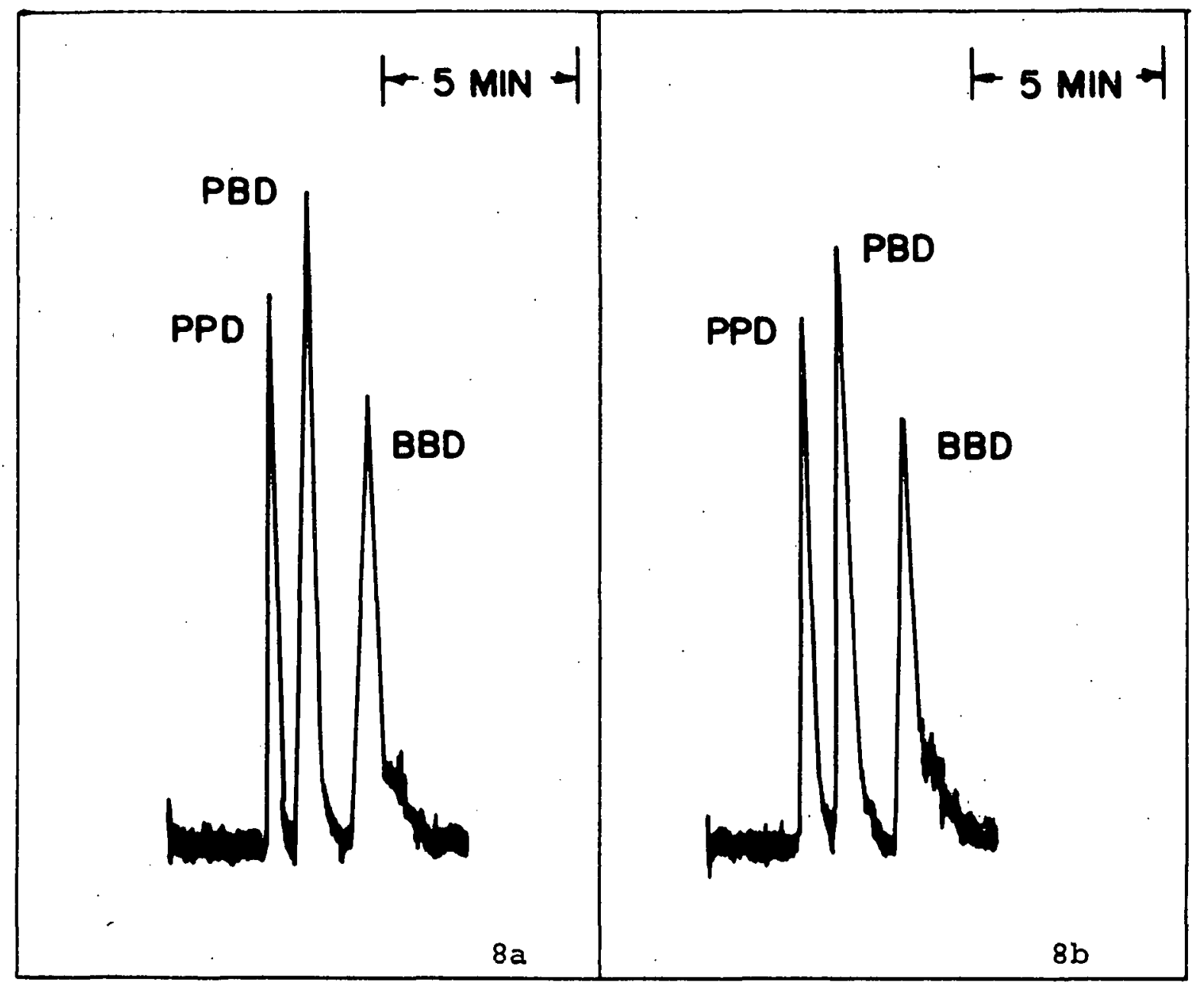

Figure 8. Chromatograms for ITPEF detection of PPD, PBD, and BBD, $100 \mu 1$ injection volume, sensitivity 100 counts per inch. (a) $2.4 \times 10^{-5} \mathrm{M}$ PPD, $1.5 \times 10^{-6} \mathrm{M}$ PBD, 4. $0 \times 10^{-6} \mathrm{M} B \mathrm{BD}$, (b) same oxadiazole concentrations but with approximately $10^{-5} \mathrm{M}$ phenol, fluorene, chrysene, and anthracene. 


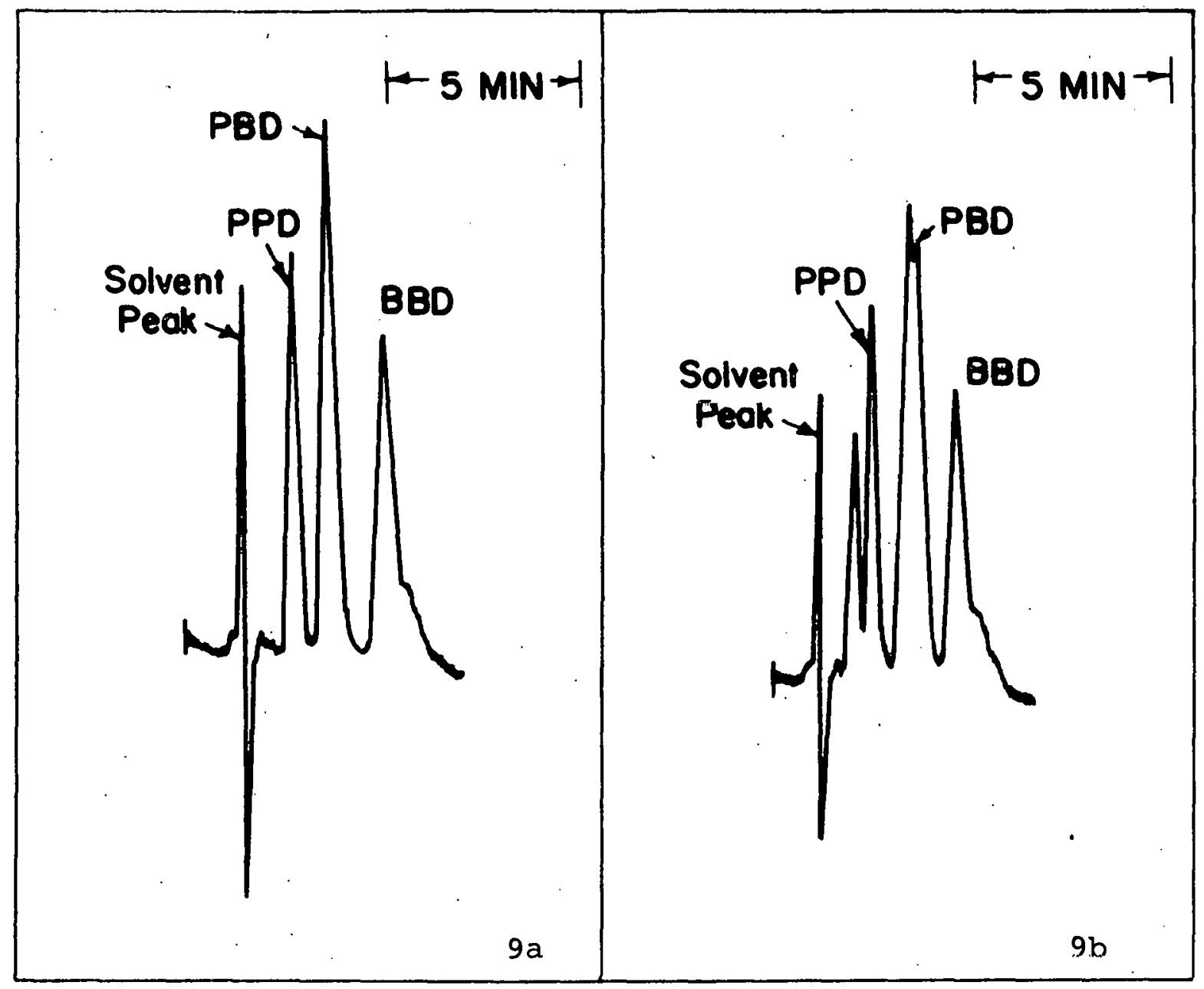

Figure 9. Chromatograms for U.V. absorbance detection of

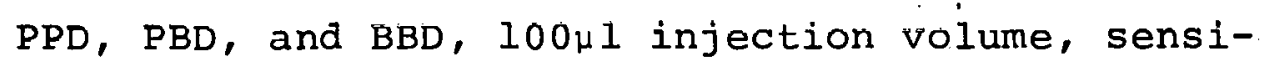
tivity 0.008 absorbance units per inch. (a) $4.0 \times 10^{-6} \mathrm{M} \mathrm{PPD}, 7.0 \times 10^{-6} \mathrm{M} \mathrm{PBD}, 1.0 \times 10^{-5} \mathrm{M} \mathrm{BBD}$, (b) same oxadiazole concentrations but with approximately $10^{-5} \mathrm{M}$ phenol, fluorene, chrysene, and anthracene. 
found with the proper output frequency and power. of course, many compounds will require laser output frequencies and powers which are not available at this point, but with the steady advancement of laser technology and twophoton absorption research more applications of LTPEF detection are possible.

In this study LTPEF detection has been shown to have detection limits and linearity of response which are comparable to U.V. absorbance detection for the strong two-photon absorbing oxadiazoles PPD, PBD, and BBD. The ITPEF detection method has been shown to be very selective meaning less solute interference and the elimination of the dependence of detector response on chromatographic parameters such as eluent composition and flow rate. 


\section{SUGGESTIONS FOR FURTHER STUDY}

To extend the applicability of this LTPEF detector new types of lasing are desirable. When an energy level system is made to have a higher population in an upper state than in a lower state a population inversion exists in the system. Under this condition radiation incident on the system can be amplified by the stimulated emission process, thereby creating a laser. The vital problem here is to make the stimulated emission predominate over spontaneous emission and absorption, since the latter two remove the population inversion. The difficulty in doing this is directly proportional to the energy difference in the system. This is one of the reasons why there are currently many lasers that operate in the I.R. or visible, but very few that lase in the U.V., which is the prime spectral region of interest for HPLC detection. This study employed an argon ion laser which is capable of 10 watts of visible radiation but only about 0.2 watts in the near U.V. (350 nm and $360 \mathrm{~nm}$ ). The U.V. excitation of certain HPLC separated molecules was accomplished via the two-photon absorption process, but this is not the only mode in which the laser can be used.

Another possible mode of operation involves using 
the visible output of the laser to excite metal complexes. Reference 23, Chp. 6 has an extensive list of fluorometric reagents which could be used to complex metal ions in stream following a cation exchange separation. Many fluorescent metal complexes absorb in the blue-green region of the visible spectrum making the argon ion laser a suitable excitation source. The problem with this type of detection lies with a nonzero background resulting from the fluorescence of the uncomplexed fluorometric reagent.

The simplest mode of operation would be using the near U.V. output of the laser (U.V. laser mirrors are needed) to excite compounds such as higher molecular weight $\mathrm{PAH}$, vitamins, or alfatoxins, which fluoresce when excited in the $350 \mathrm{~nm}$ to $360 \mathrm{~nm}$ region. While the U.V: output of the laser is a couple of orders of magnitude less than the visible sutput it is still a relatively intense light source and, most likely, capable of improving detection limits. Since most compounds have a U.V. cut-off below $350 \mathrm{~nm}$ this mode of detection would be very selective resulting in simplified chromatograms.

A final mode of operation which warrants further study would be frequency doubling the $5145 \AA$ line of 
the laser. When cooled to approximately $-11^{\circ} \mathrm{C}$ phase matching in a $\mathrm{KH}_{2} \mathrm{PO}_{4}$ crystal occurs for radiation at 5145\%. Under the phase matched condition second harmonic generation with an efficiency of 1 percent per watt of radiation is possible. The most common light source frequency in photometric HPLC detection is $254 \mathrm{~nm}$ (most chromaphores absorb at this wavelength). The frequency doubled $5145 \AA$ radiation of the laser $(257 \mathrm{~nm})$ would then be a versatile light source for fluorometric detection. Again the relatively high intensity of this radiation could result in lower detection limits. 


\section{BIBLIOGRAPHY}

1. D. R. Baker, R. C. Williams, and J. C. Steichen,

J. Chromatogr. Sci., 12, 499 (1974).

2. J. Polesuk and D. G. Howery, J. Chromatogr. Sci., 11, 226 (1973).

3. S. H. Byrne, Modern Practice of Liguid Chromatography, J. J. Kirkland, ed. Wiley Interscience, New York, New York, 1971, Chapter 3 .

4. M. N. Munk, J. Chromatog. Sci., 8, 491. (1970).

5. J. N. Done, J. H. Knox, and J. Loheac, Applications of High Speed Liguid Chromatography, J. Wiley and Sons, New York, New York, 1974, p. 4 .

6. M. Krejci and N. J. Pospisilova, J. Chromatogr., 73, 105 (1972).

7. S. G. Perry, R. Amos, and P. I. Brewer, Practical Liguid Chromatography, Plenum Press, New York, New York, 1972, p. 194 .

8. E. D. Pellizzari and C. M. Sparachino, Anal. Chem. 45, 378 (1973).

9. C. G. Vaughan, B. B. Wheals, and M. J. Whitehouse, J. Chromatogr., 78, 203 (1973).

10. C. G. Vaughan, B. B. Wheals, and M. J. Whitehouse, J. Chromatogr., 106, 109 (1975).

11. W. Strubert, Chromatographia, 6, 205 (1973).

12. R. D. Conlon, Anal. Chem., 41, 107A (1969).

13. M. A. Fox and S. W. Staley, Anal. Chem., 48, 992 (1976).

14. D. D. Chilcote and J. E. Mrochek, Clin. Chem., $18,778(1972)$.

15. R. M. Cassidy, D. S. LeGay, and R. W. Frei, J. Chromatogr. Sci., 12, 85 (1974). 
16. R. J. Perchalski, J. D. Winefordner, and B. J. Wilder, Anal. Chem. 47, 1993 (1975).

17. W. Dunges, G. Naundorf, and N. Seiler, J. Chromatogr. Sci., 12, 655 (1974).

18. R. W. Frei and J. F. Lawrence, J. Chromatogr., 83, 32 (1973).

19. J. F. Lawrence and R. W. Frei, J. Chromatogr. 93, 253 (1974).

20. G. Veening, J. Chem. Educ., 47, A749 (1970).

21. J. C. Steichen, J. Chromatogr., 104, 39 (1975).

22. R. M. Cassidy and R. W. Frei, J. Chromatogr., 72, 293 (1972).

23. G. G. Guilbault, Practical Fluorescence, Marcel Dekker, Inc., New York, New York, 1.973, p. 138.

24. J. J. Kirkland, Anal. Chem. 43, 36A (1971).

25. D. C. Locke, J. Chromatogr. Sci., 11, 120 (1973).

26. J. N. Done, G. J. Kennedy, and J. H. Knox, Nature, 237, 77 (1972).

27. A. Pryde, J. Chromatogr. Sci., 12, 486 (1974).

28. E. Grushka, (ed.), Bonded Stationary Phases in Chromatography, Ann Arbor Science Publishers, Inc., Ann Arbor, Michigan, 1974.

29. I. Idalasz and I. Sebestian, Angew. Chem., 81, 464 (1969).

30. M. Gurken, Amer. Lab. 9 (1), 29 (1977).

31. K. Karch, I. Sebestian, I. Halasz, and H. Engelhardt, J. Chromatogr., 122, 171 (1976).

32. K. Karch, I. Sebestian, and I. Halasz, J. Chromatogr., $122,3(1976)$.

33. R. E. Leitch and J. J. Destefano, J. Chromatogr. Sci. 11, 105 (1973). 
34. Chromatography Notes, Waters Associates, Milford, Mass., 3 (4).

35. J. Schmit, R. Henry, R. Williams, and J. Dieckman,

J. Chromatogr. Sci., 9, 645 (1971).

36. I. Jane and B. Wheals, J. Chromatogr. 84, 181 (1973).

37. Waters Associates, Milford, Mass., Publication No. DS72-015.

38. R. Williams, Dupont Liquid Chromatography Methods Bulletin 820M13, October 1972 .

39. W. Rzeszotarski and A. Mauger, J. Chromatogr. 86, 246 (1973).

40. A. Krstulovic, D. Rosie, and P. Brown, Anal. Chem. 48 , 9, 1383 (1976).

41. M. Copper-Mayer, Ann. Phys. 9, 273 (1931).

42. H. Mahr, Quantum Electronics, H. Robin and C. Tang, Ed., Vol. 1, Part A, Academic Press, New York, New York; 1975, Chapter 4.

43. D. Kleiman, Phys. Rev., 125, 87 (1962).

44. W. M. MCClain, Acc. Chem. Res., I, 199 (1974).

45. R. S. Drago Physical Methods in Inorganic Chemistry, Reinhold Publishing Corp., New York, New York, 1965, p. 148 .

46. R. L. Swofford, A Digitized Two-Photon Spectrometer and Its Application to Organic Molecules, Ph.D. Dissertation, Univ. of California, Berkeley (1973) p. 9.

47. W. Kaiser and C. Garrete, Phys. Rev. Letters, 7, 229 (1961).

48. J. Hopefield, J. Warlock, and K. Park, Phys. Rev. Letters, 11, 414 (1963).

49. M. Inoue and Y. Toyozawa, J. Phys. Soc. Japan, 20, 363 (1965). 
51. A. Gold, Proc. Int. School Phys., Enrico Fermi Course 42: Quantum Optics, R. J. Glauber, Ed., Academic Press, New York, New York, 1969.

52. F. Biraben, B. Cagnac, and G. Grynberg, Phys. Rev. Lett. 32, 643 (1974).

53. H. V. Malmstadt, M. I. Franklin, and G. Horlick, Anal. Chem. 44, 63A (1972).

54. M. I. Franklin, G. Horlick, and H. V. Malmstadt, Anal. Chem. 41, 2 (1969).

55. Waters Associates, Milford, Mass., Manual No. CU27386 Rev. B (1976).

56. B. A. Lengyel, Lasers, J:. Wiley and Sons, New York, New York, 1971, Chapter 9.

57. A. E. Siegman, An Introduction to Lasers and Masers, McGraw-Hill Book Co., New York, New York, I971, p. 317 . 